DIW BERLIN

Discussion Papers

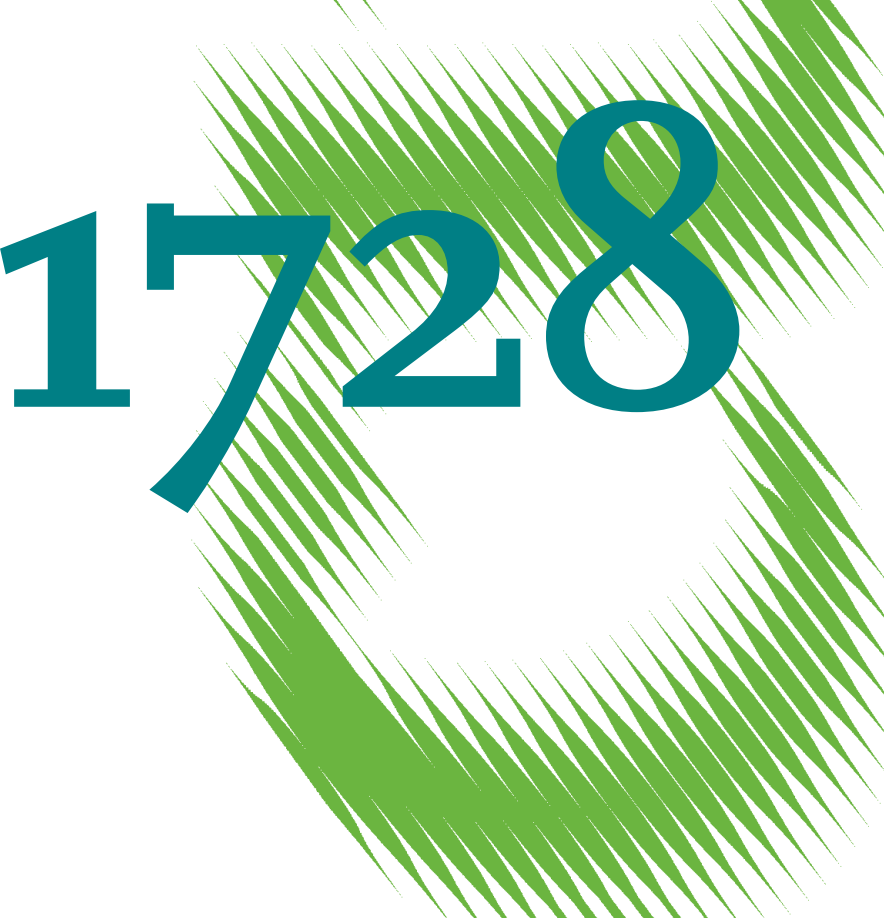

Liquidity Risk and Yield Spreads of Green Bonds 
Opinions expressed in this paper are those of the author(s) and do not necessarily reflect views of the institute.

IMPRESSUM

(C) DIW Berlin, 2018

DIW Berlin

German Institute for Economic Research

Mohrenstr. 58

10117 Berlin

Tel. +49 (30) $89789-0$

Fax +49 (30) $89789-200$

http://www.diw.de

ISSN electronic edition 1619-4535

Papers can be downloaded free of charge from the DIW Berlin website:

http://www.diw.de/discussionpapers

Discussion Papers of DIW Berlin are indexed in RePEc and SSRN:

http://ideas.repec.org/s/diw/diwwpp.html

http://www.ssrn.com/link/DIW-Berlin-German-Inst-Econ-Res.html 


\title{
Liquidity risk and yield spreads of green bonds
}

\author{
Febi Wulandari $^{a} \quad$ Dorothea Schäfer $^{a, b, d} \quad$ Andreas Stephan ${ }^{a, b, c *}$ \\ Chen $\operatorname{Sun}^{a}$ \\ ${ }^{a}$ Jönköping International Business School, ${ }^{b}$ German Institute for Economic Research DIW \\ Berlin, ${ }^{c}$ Ratio institute, ${ }^{d}$ CERBE
}

March 12, 2018

\begin{abstract}
This study analyses how liquidity risk affects bonds' yield spreads after controlling for credit risk, bond-specific characteristics and macroeconomic variables. Using two liquidity estimates, LOT liquidity and the bid-ask spread, we find that, in particular, the LOT liquidity measure has explanatory power for the yield spread of green bonds. Overall, however, the impact of LOT decreases over time, implying that, nowadays liquidity risk is negligible for green bonds.
\end{abstract}

Keywords: Green Bond, Liquidity Risk, Yield Spread, Sustainable Investment, Fixed Income Security, Financial Innovation

JEL: G12, G32

*Corresponding author: andreas.stephan@ju.se 


\section{Introduction}

This study investigates the effects of the liquidity premium on the green bond yield spreads. We control for credit risk, as well as bond-specific and macroeconomic factors. Liquidity concerns may be pertinent in green bonds market due to (1) its disproportional thinness, and (2) its unclear solvency profile.

The demand for green bonds is likely to surpass the supply due to investors' need to address the ESG (Environmental, Social, and Governance) and SRI (Social Responsible Investment) mandates. In addition, green bonds show low correlation with other fixed income securities and provide diversification benefits to investors (Inderst et al. 2012). Despite the rapid growth of green bonds' demand in the market, the supply of green bonds is insufficient due to: (1) a lack of fiscal incentive for green investment (Zerbib 2017), and (2) a lack of an official and universal classification system for green bonds that is in accordance with market based frameworks, such as, the Green Bonds Principle (Cochu et al. 2016). The latter might cause opacity on the definition of "green" investment and bonds, and issuers will be subject to additional transaction costs, e.g., contracting with external reviewers pre and post green bonds' issuance. This leaves the issuance of green bonds less attractive than that of conventional bonds. Due to the shortage of green bonds' supply in the market, issuers are able to offer green bonds at lower interest rates, relative to the wider bonds market (Preclaw \& Bakshi 2015a, Bloomberg 2017, Zerbib 2017). However, the shortage of supply and the excess of demand in green bonds market imply a thin market, and, liquidity becomes relevant. Consequently, a liquidity premium may emerge.

The second factor that may cause illiquidity in the green bonds market, such as, a lack of credit risk profile, is partly endogenous for the issuers. Cochu et al. (2016) put forward that the green bonds' credit risk profile is unclear, since: (1) transparency in the reporting of green projects is lacking, and (2) the ratings of green bonds rely heavily on the balance sheets of the issuers instead of green project investment. A green project usually involves experimental innovation activities that are considered less ma- 
ture, and due to a scarcity of evidence on the performance of green projects, investors might deem the green bonds as more risky than investing in conventional bonds. The lack of reporting transparency signifies the existence of private information that results in an increase of adverse selection costs (Lin et al. 2012). Both Bagehot (1971) and Amihud \& Mendelson (1980) argue that transaction costs and adverse selection costs may trigger illiquidity and cause a liquidity premium.

To this end, we use two alternative liquidity measures in order to analyze effects of liquidity shortage on bond yield spreads: the LOT liquidity measure proposed by Chen et al. (2007), and the bid-ask spread (Amihud \& Mendelson 1986, Brandt \& Kavajecz 2004). By modeling the return generating process, the LOT liquidity measure can capture additional information, such as, market impact costs, commission costs and opportunity costs (Utz et al. 2016). We use fixed effects panel regressions with robust clustered standard errors at bond level, and control for year effects. In addition, we provide estimates of the pooled OLS model for panel data.

Our study has important practical implications for green bond issuers. Specifically, if issuers know the impact of liquidity risk, they may prevent increased risk by reducing the source of adverse selection cost, e.g., by increasing transparency of green projects' financial performance. The success of sustainable and low-carbon projects, also relies on funding costs. By avoiding increased liquidity risk, ultimately the issuers will be able to enjoy affordable cost of debt when financing green projects.

The remainder of this article is organized as follows. Section 2 presents background and theory. Section 3 presents data and method. Section 4 provides results. Section 5 concludes.

\section{Background}

The green bonds market has grown rapidly since the first issuance of green bonds by the World Bank in 2008. However, financing a climate-resilient economy comes with 
the cost of adaption and mitigation efforts. This section presents background information regarding several crucial issues stemming from the green bonds market: climate challenge and related policy responses, the financing required to achieve a sustainable and climate-resilient economy, the role of the green bonds market and the theory used in this paper.

\subsection{The climate challenge and policy}

In the decades following the industrial revolution of the early 19th century, there has been an exponential growth in population, income and consumption. In addition, technological progress made economies increasingly dependent on exhaustible resources, such as, fossil fuels and uranium, among others. The growing use of fossil fuels has contributed to an increase of greenhouse gas (GHG) emissions, contributing to a general global warming trend. According to (IPCC 2013), the average global temperature has increased by 0.85 degrees Celsius between 1880 and 2012. It has been confirmed that this warming is impacting the planet in a variety of ways. The sea level is rising causing an increase in coastal flooding, there are more frequent heat waves and more numerous wildfires, just to name a few things (Flaherty et al. 2017).

The challenge for policymakers is to reduce global warming by 2 degrees Celcius relative to pre-industrial levels (OECD 2017). One of the primary strategies to achieve this goal is to reduce GHGs. In order to reduce the GHG emissions in a timely manner policymakers have proposed several market-based policy tools to internalize GHG emissions' externality. Carbon pricing is a well-known incentive designed to encourage climate mitigation. Greater emission reductions will be achieved when a firm is able to abate cheaply, thus, minimizing the cost of climate change mitigation (Buchanan \& Tullock 1975). A firm that is able to take advantage of carbon pricing to equalize the marginal costs incurring when achieving GHG reductions, may be motivated to reduce GHG emissions even further. The transition to green technologies, however, cannot be solved by carbon pricing alone. Adaption effort is the main principle of the Frame- 
work Convention on Climate Change (Kane \& Shogren 2000). Green bonds can help the adaption to climate change, as well as, the transition to green technologies, which neither can be solved by carbon pricing alone.

The European Union (EU) has been leading the transition to a sustainable and low carbon economy, and has defined its 2050 decarbonization goals. Sustainable issues have been addressed in its financial policies since 2014 by introducing ESG (Environmental, Social, and Governance) requirements in its directive 2014/95/EU (the HighLevel Expert Group 2017). The current lack of a universal classification system to define green investments is considered to be an impediment to fostering investor confidence. However, the EU is taking steps to develop policies that will establish an official European green bonds' standard that is based on widely accepted market-based guidelines. The Green Bond Principles is one such step in this direction.

\subsection{Financing needs}

According to Mackenzie \& Ascui (2009), it is estimated that by 203010 trillion USD will be needed to finance the necessary efforts to meet the climate goal. According to Clapp (2014), the world will need to invest 100 billion USD annually in green investment by 2020 in order to achieve a meaningful mitigation effort. Institutional investors have approximately 100 trillion USD worth of assets under management, indicating that the wealth to fund green technologies exists. The costs of modifying transportation systems and developing new infrastructures are the main concerns that arise when discussing how to fund the transition from the entrenched fossil-fuel based technologies to green renewable energy technologies (Flaherty et al. 2017). The second concern is the opportunity cost incurred by firms when forgoing relatively low cost fossil-fuel based technologies. Flaherty et al. (2017) suggest that governments will play a significant role in setting the standards and enforcing regulations to foster growth in green investment and activities. 


\subsection{Green bonds market and its challenges}

Globally, around 80 trillion USD of bonds are under management by institutional investors, such as, pension funds, insurance agencies, fund managers among other institutional investors (the World Bank 2015). Green bonds constitute only $0.13 \%$ of the total bonds market. Despite green bonds' small share in the wider bond market, the demand in green bonds is growing due to investors' needs to diversify their portfolio against climate risk and to increase the portfolio's ESG (Environment, Social, and Governance) profile. As mentioned in the previous section, for instance, the EU has encouraged market participants to invest in sustainable and low-carbon projects by addressing ESG requirements in the EU directive on disclosure of non-financial and diversity information by certain large undertakings and groups (2014/95/EU). Further guidelines on the disclosure of ESG information has been adopted by the European Commission and supplied in the EU directive 2014/95/EU. The guideline will be effective as of 2018 and this aims to increase corporate transparency reporting and performance as well as achieving a greener and more sustainable economy (EUROPA 2017)

Seventy-six percent of all green bond issuances are from multilateral development banks, such as, the World Bank, Nordic Investment Bank, and European Investment Bank. Corporate entities issue 16\%. Other suppliers of new green bonds are governments and municipalities. They make up for $8 \%$ of the total issuance. The total value of climate-themed bonds is about 694 billion USD. Two different categories of climatetheme bonds exist, so called labeled and unlabeled green bonds. Based on a report by CBI (2015), labeled and unlabeled green bonds account for $17 \%$ and $83 \%$ of climatealigned bonds, respectively. Furthermore, according to Kane \& Shogren (2000) there are three types of green bonds based on the repayment sources, namely, asset-backed bonds, government-backed bonds, and covered green bonds. Asset-backed bonds' repayment relies on particular revenue streams, such as, fees and taxes, and the fund can be channelled into green or non-green projects. Government-backed bonds include municipal and government type of green bonds that are issued to fund sustainable and 
low-carbon projects. Covered green bonds are backed by the issuers' balance sheets. Lastly, green project bonds are a further category (CBI 2015). They are backed by the specific green project's balance sheets, that is, repayment depends on the project's performance.

Cochu et al. (2016) indicate that the current green bonds market faces a few barriers that may constrain its future development and growth. First, there is a shortage of green bonds and green projects in the pipeline. The supply of green bonds is currently insufficient to meet the high demand from the investors. A study by Zerbib (2017) investigates the yield difference between green and conventional bonds. It confirms a negative average green bonds premium, indicating that the demand for green bonds relative to supply exceeds that of conventional bonds. Thus, the current issuance volume of green bonds is not sufficient. Reports by Preclaw \& Bakshi (2015b) and Bloomberg (2017) find a significant negative premium of -17 bp,and -25 bp, respectively, for green bonds. In contrast, Karpf \& Mandel (2017) who study the US municipal bonds premium, find a positive premium for green bonds. In this category, the average yield of green bonds is higher by $7.8 \mathrm{bp}$ in comparison to non-green bonds. In the light of these contradictory findings the question arises whether illiquidity problems can be responsible for positive yield spreads relative to non-green bonds.

Second, with a lack of consensus on how to identify "green" bonds, investors rely on the external reviewers and their capability and willingness to follow the marketbased guidelines, fixed in the Green Bonds Principle and the Climate Bonds Initiative framework. Cochu et al. (2016) state that additional transaction costs in issuing green bonds renders green bonds less attractive than conventional bonds.

Third, Cochu et al. (2016) state that the green investment risk profile is unclear, since most of green bonds are covered bonds that are backed by the issuers' financial performance, instead of the performance of the underlying green investment. Furthermore, there exists a lack of transparent reporting in green investments. In the case of green projects bonds that are backed by the green projects' financial performance, in- 
vestors may perceive investing in this type of green bonds to be riskier than investing in other assets, e.g., conventional bonds. A green project usually involves experimental innovation activities that are considered less mature, and due to a scarcity of evidence on the performance of green projects, investors might deem the green bonds as more risky than investing in conventional bonds.

\subsection{Liquidity costs and yield spreads}

It is commonly assumed that the yield spread represents a significant proportion of default risk. Practitioners frequently draw conclusions regarding default probabilities from yield spreads. However, default risk alone may not be able to explain the variation of bonds' yield spreads. Longstaff et al. (2005) reveal that the failure of the structural model is due to excluding liquidity from the model. A vast body of literatures confirms that an improvement in firms' market liquidity leads to a tighter corporate yield spread (Collin-Dufresn et al. 2001, Campbell \& Taksler 2003, Longstaff et al. 2005, Chen et al. 2007, Dick-Nielsen et al. 2012).

Amihud et al. (2006) explains that the term liquidity means "smooth trading of securities". Trading costs, search problems, and information asymmetry or adverse private information and inventory risk causes illiquidity in the market (Bagehot 1971, Amihud \& Mendelson 1980). When private information exists the market consists of informed and uninformed traders. According to Bagehot (1971) informed traders always win in the market, therefore, the uniformed traders lose as the informed traders charge a higher bid-ask spread. Higher bid-ask spreads are associated with illiquidity. Lin et al. (2012) show that the existence of information asymmetry or private information is positively associated with liquidity risk.

The above considerations, the disproportional thinness, the unclear solvency profile, and additional transaction costs, e.g., the cost of keeping the "green" label suggest that liquidity risks are particularly pronounced in the green bond markets. In line with the literature, we hypothesize that green bonds' liquidity significantly influence the 
yield spreads of the bonds, while controlling for credit risk proxy, bond-specific, and macroeconomic factors.

\section{Data and method}

\subsection{Data description}

Our sample consists of 64 labeled green bonds that are listed on the London Stock Exchange and on the Luxembourg Stock Exchange, and 56 conventional bonds traded on the Luxembourg Stock Exchange having similar characteristics to our green bonds. In order to be labeled as "green", the climate bonds' proceeds have to be in accordance with the framework of Green Bond Principles (GBP) and/or Climate Bonds Intiative (CBI). ${ }^{1}$ We use a sample of labeled green bonds in our study, since we would like to capture the true "greenest" of the bonds. Climate-aligned bonds are susceptible to "greenwashing" issues, thus, by using the labeled green bonds in this study we minimize the chance of investigating bonds that lack environmental benefits.

We use ISINs of green and conventional bonds to match with firm-level issuer data collected from Bureau Van Dijk's Amadeus. Some green bonds are issued by multilateral organizations, and municipalities. In these cases firm-level data are hand collected. Table 1 presents a list of variables, descriptions and data sources.

\footnotetext{
${ }^{1}$ The Green Bond Principles is a key framework that provides guidelines for launching credible green bonds. The GBP consists of four components: use of proceeds, project evaluation process, management of proceeds and reporting. The GBP and CBI require third party reviews to assure the eligibility of green projects
} 
Table 1: This table describes the data used in this study.

\begin{tabular}{llc}
\hline Variables & Descriptions & Source \\
\hline Yield Spread & $\begin{array}{l}\text { The difference between bond yield and government } \\
\text { bond yield }\end{array}$ & (a) \\
LOT & $\begin{array}{l}\text { LOT liquidity generated by modelling the returns } \\
\text { generating process }\end{array}$ & (a) \\
$R_{j, t}(1)$ & Daily return of a bond $j$ in year $t$ based on clean prices & (a) \\
$D_{j, t}(1)$ & Modified duration of a bond $j$ in year $t$ & (a) \\
$\Delta R_{f, t}(1)$ & Daily change of 10-year Eurozone rate or 10-year US & (a) \\
$\Delta$ Index $(1)$ & treasury notes or 10 year Riskbank treasury bills & \\
Bid-Ask & Thily return of Eurostoxx 50 or FTSE 100 index \\
& (spread) of both prices & (a) \\
Maturity & Time to maturity (remaining life of bonds) & (a) \\
Government & 1-year government bonds rates respective to bonds' & (a) \\
Bond & currencies & (a) \\
Term Slope & Difference between 10-year and 2-year government & (a) \\
bonds' rates & Numeric values of bonds' ratings ranging between 1(AAA) \\
Rating Scale & and 7 (Baa3). Credit ratings come from Moody's ratings & (a) \\
Income/Sales & Operating income divided by sales & (b) \\
Debt/Assets & Long term debts divided by total assets & (b) \\
Debt/Capital & Total liabilities divided by capital & (b) \\
Interest Coverage & EBI to interest expense & (b) \\
\hline
\end{tabular}

Note: ${ }^{(1)}$ Used as input variables for generating the LOT liquidity measure by means of returns generating process. (a) Thomson Reuter's Datastream, (b) Bureau VanDijk's Amadeus Database 


\subsection{The liquidity proxies}

However, the bid-ask spread has its limitations. The data used to calculate the spreads is sometimes unavailable. Therefore, especially thinly traded bonds' bid-ask spreads lack credibility. The LOT liquidity model is a measure that can be substituted for the bid-ask spread. It is able to capture and estimate costs that may influence informed trading, namely, opportunity costs, commission costs and market impact costs. The other benefit is that the LOT liquidity measure can provide liquidity estimation for bonds that are almost mature and/or thinly traded. Both LOT liquidity estimation and bid-ask spreads are positively correlated (Chen et al. 2007). In order to measure the variation of liquidity on green bonds' yield spreads and obtain robust results, we apply both liquidity measures. ${ }^{2}$

\subsection{The LOT model}

Lesmond et al. (1999) develop a liquidity estimator (LOT) based on the assumption of informed trading on non-zero-return days and the absence of informed trading on zero-return days. The LOT liquidity model estimates the transaction costs for marginal traders from both the buy and sell sides. According to Amihud \& Mendelson (1986), the liquidity premium is defined by the difference between the "true" value of bonds and the observed value of bonds. Under the assumption of perfect information, an informed trader will only execute (buy) a bond $\mathrm{j}$ at times $t$ when the value of information exceeds the buy side transaction costs $a_{2, j}$. In the case of a sell-side transaction, its cost $a_{1, j}$ should be greater than the information value. When the true return $R_{j, t}^{\star}$ is between $a_{1, j}$ and $a_{2, j}$, the observed returns $R_{j, t}$ will be zero. Given the assumption of

\footnotetext{
${ }^{2}$ There are only a few liquidity proxies that are commonly used in the past literatures, such as, Range measure (Han \& Zhou 2008) and Amihud measure (Amihud 2002). However, due to our data limitation we cannot use those liquidity proxies. Furthermore, the aforementioned liquidity proxies require data on the daily trading volumes that are not available for green bonds. The intraday trading volumes are usually acquired from TRACE, yet green bonds are not listed in TRACE. Thus, we are not able to obtain such intraday data.
} 
perfect information, the relationship between $R_{j, t}$ and $R_{j, t}^{\star}$ is given as follows:

$$
\begin{aligned}
& R_{j, t}=R_{j, t}^{\star}-a_{1, j} \quad \text { if } \quad R_{j, t}^{\star}<a_{1, j} \quad \text { and } \quad a_{1, j}<0 \\
& R_{j, t}=\quad 0 \quad \text { if } a_{1, j} \leq R_{j, t}^{\star} \leq a_{2, j} \\
& R_{j, t}=R_{j, t}^{\star}-a_{2, j} \quad \text { if } \quad R_{j, t}^{\star}>a_{2, j} \quad \text { and } \quad a_{2, j}>0 \text {. }
\end{aligned}
$$

The "true" returns of the bonds are computed by following the two-factor model of (Chen et al. 2007). The two factors are the risk-free rate and the equity market return, assuming that a green bond is a hybrid between a risk-free bond and underlying equity. Following Jarrow (1978), all risk coefficients are scaled by duration to acquire stable estimation coefficients. The return generating process is given by

$$
R_{j, t}^{\star}=\beta_{j, 1} D_{j, t} \Delta R_{f, t}+\beta_{j, 2} D_{j, t} \Delta \operatorname{Index}_{t}+\epsilon_{j, t}
$$

The estimations of the sell and buy transaction costs, $a_{1, j}$ and $a_{2, j}$, are performed by maximizing $\log$-likelihood function of $L\left(a_{1, j}, a_{2, j}, \beta_{j, 1}, \beta_{j, 2}, \sigma_{j} \mid R_{j, t}, \Delta\right.$ Index $)$. Parameter $\sigma_{j}$ is the unknown standard deviation of the error term, $\epsilon_{j, t}$. The log-likelihood function is given as

$$
\begin{aligned}
\ln L= & \sum_{1} \ln \frac{1}{\left(2 \pi \sigma_{j}^{2}\right)^{\frac{1}{2}}}-\sum_{1} \frac{1}{2 \sigma_{j}^{2}}\left(R_{j, t}+a_{1, j}-\beta_{j, 1} D_{j, t} * \Delta R_{f, t}-\beta_{j, 2} D_{j, t} * \Delta \text { Index }_{t}\right)^{2} \\
& +\sum_{2} \ln \frac{1}{\left(2 \pi \sigma_{j}^{2}\right)^{\frac{1}{2}}}-\sum_{2} \frac{1}{2 \sigma_{j}^{2}}\left(R_{j, t}+a_{2, j}-\beta_{j, 1} D_{j, t} * \Delta R_{f, t}-\beta_{j, 2} D_{j, t} * \Delta \text { Index }_{t}\right)^{2} \\
& +\sum_{3} \ln \left(\Phi_{2, j}-\Phi_{1, j}\right)
\end{aligned}
$$

where $\Phi_{i, j}$ denotes the cumulative distribution function for each bond-year evaluated at $L\left(a_{i, j}-\beta_{j, 1} D_{j, t} * \Delta R_{f, t}-\beta_{j, 2} D_{j, t} * \Delta\right.$ Index $\left._{t}\right) / \sigma_{j}, \sum_{1}$ (region 1) denotes the negative nonzero measured returns, $\sum_{2}$ (region 2) denotes the positive nonzero measured returns, and $\sum_{3}$ (region 3 ) denotes the zero measured returns.

The LOT liquidity measure for bond $j$ is simply the difference between the percent 
buying cost and the percent selling cost

$$
L O T_{j}=a_{2, j}-a_{1, j}
$$

The average of sell trades, buy trades and LOT liquidity estimate for conventional and green bonds are reported in Tables 6 and 7.

\subsection{The yield spread determinants}

We estimate pooled OLS and fixed-effects panel regressions with robust clustered standard errors at bond level, we also control for year effects. More specifically, we employ four different models. Pooled OLS regression are performed for green bonds in Model 1, and for conventional bonds in Model 2. Model 3 represents a fixed-effects panel regression for both green and conventional bonds. In the final Model 4 , we apply a fixed-effects panel regression for green bonds. The following equation describes our regression equation for Models 1 and 2,

$$
\text { YieldSpread }_{i t}=f\left(\text { Year }_{t}, L O T_{i t}, \text { BidAsk }_{i t}, \text { Controls }_{i t}\right)
$$

where controls are Maturity ${ }_{i t}$, GovernmentBond $_{i t}$, TermsSlope $_{i t}$, RatingScale $_{i t}$, Income/Sales $_{i, t-1}$, Debt/Assets $_{i, t-1}$, Debt/Capital $_{i, t-1}$, InterestCoverage $_{i, t-1}$.

Model 3 (Equation 5) is estimated both for green and conventional bonds. Here, the interaction variables between liquidity measures and bond types are included in order to check how much each liquidity estimate affects the yield spreads of each bond category.

$$
\begin{aligned}
\text { YieldSpread }_{i t}= & f\left(\text { Year }_{t}, \text { Bond }_{i}, \text { BidAsk }_{i t} \times \text { Green }_{i},\right. \\
& L T_{i t} \times \text { Green }_{i}, \text { BidAsk }_{i t} \times \text { Conventional }_{i}, \\
& \left.L T_{i t} \times \text { Conventional }_{i}, \text { Controls }_{i t}\right)
\end{aligned}
$$

where Bond $_{i}$ is a bond-specific fixed effect. In Model 4 (Equation 6), which is only 
estimated for green bonds, an interaction variable between year and LOT liquidity is included. This allows us to estimate the impact of LOT liquidity on yield spread for each year using a fixed effects regression model

$$
\text { YieldSpread }_{i t}=f\left(\text { Year }_{t}, \text { Bond }_{i}, L_{\text {SOT }} \text { it } \times \text { Year }_{t}, \text { Controls }_{i t}\right) \text {. }
$$

\section{Empirical results}

\subsection{Summary statistics}

Based on the summary statistics and $t$-tests presented in Table 2, yield spreads between conventional and green bonds are not significantly different between the years 2013-2015. However, in 2016, the difference between conventional and green bond yield spreads is significant, showing that the yield spread of conventional bonds is higher by 69.2 bp compared to green bonds. Our result is consistent with a study by Zerbib (2017) who investigates a combined sample of both labeled and unlabeled green bonds. This study finds that, on average, green bonds' yield spread is lower than that of conventional bonds. Zerbib (2017) find a negative green bonds premium that ranges between $-5 \mathrm{bp}$ to $-30 \mathrm{bp}$.

Interestingly, the $t$-tests show that both liquidity measures, the bid-ask spread and the LOT liquidity measure, suggest that conventional bonds are less liquid than green bonds, and the differences are significant for all three years under investigation, 2014, 2015 and 2016.

Table 3 reports the descriptive statistics of green and conventional bonds' characteristics. The results show that our sample of green and conventional bonds possess similar characteristics. The average time to maturity of green bonds is 8.5 years, with a standard deviation of 3.85 years. Conventional bonds' average time to maturity is 7 years, with a standard deviation of 2.11 years. Those features indicate that both green and conventional bonds' maturity belong to the class of medium maturity bonds but 
Table 2: Summary statistics and $t$-test of conventional and green bonds over the sample period 2014-2016.

\begin{tabular}{c|lcccc}
\hline \multicolumn{1}{c}{ Year } & & $\mathbf{2 0 1 3}$ & $\mathbf{2 0 1 4}$ & $\mathbf{2 0 1 5}$ & $\mathbf{2 0 1 6}$ \\
\hline Yield spread (bp) & & & & & \\
Conventional & Mean & 158.2 & 89.2 & 53.3 & 139.6 \\
& \#bonds & 18 & 25 & 31 & 42 \\
Green & Mean & 59.4 & 41.4 & 52.1 & 70.4 \\
& \#bonds & 3 & 15 & 38 & 64 \\
& Difference & 98.9 & 47.8 & 1.2 & $69.2^{*}$ \\
& t-stat & 1.3 & 1.2 & 0.03 & 1.6 \\
LOT (bp) & & & & & \\
Conventional & & & & & \\
& Mean & 25.2 & 22.0 & 26.4 & 33.5 \\
Green & \#bonds & 18 & 25 & 31 & 42 \\
& Mean & 18.1 & 15.1 & 18.0 & 19.5 \\
& \#bonds & 3 & 15 & 38 & 64 \\
& Difference & 7.1 & $6.9^{*}$ & $8.4^{* *}$ & $14.1^{* * *}$ \\
BidAsk (bp) & t-stat & 0.74 & 1.54 & 1.75 & 2.38 \\
Conventional & & & & & \\
& & & & & \\
Green & Mean & 73.2 & 53.4 & 42.1 & 71.1 \\
& \#bonds & 18 & 25 & 31 & 42 \\
& Mean & 72.1 & 30.1 & 28.3 & 30.5 \\
& \#bonds & 3 & 15 & 38 & 64 \\
& Difference & 1.1 & $23.4^{* * *}$ & $13.8^{* * *}$ & $40.6^{* * *}$ \\
& t-stat & 0.06 & 2.71 & 2.99 & 3.25 \\
\hline
\end{tabular}

Notes: Difference $e^{a}$ shows the difference of mean between conventional and green and bonds. *, ** and ${ }^{* * *}$ denote significance at $10 \%, 5 \%$ and $1 \%$ level, respectively. 
are considerably heterogeneous. The average issue volume of green and conventional bonds shows that both bond types are characterized by high volume issuances. The green bonds' average issue volume is 710 million, 1,222 million, and 464 million denominated in EUR, SEK and USD respectively. The conventional bonds' average issue volume is 711 million EUR. Green bonds have an average rating scale of 1.33, while the conventional bonds have a higher average scale of 1 . Both green and conventional bonds are investment grade bonds that have a maximum numeric rating scale of 7 , equivalent to Baa3 (Moody's rating).

Table 3: Descriptive statistics of conventional and green bonds time-invariant characteristics in the year of bond issuance

\begin{tabular}{lrrrrrrrr}
\hline Variables & Obs & Mean & Median & SD & Min & Max & Skewness & Kurtosis \\
\hline Conventional & & & & & & & & \\
Maturity & 56 & 8.48 & 8 & 2.11 & 3 & 12 & -0.22 & 2.46 \\
Rating Scale & 56 & 2.38 & 2 & 2.65 & 0 & 7 & 0.49 & 1.57 \\
Volume & 56 & 711 & 708 & 213 & 778 & 1000 & -0.82 & 4.1 \\
& & & & & & & & \\
Green bonds & & & & & & & & \\
Maturity & 64 & 6.98 & 6 & 3.85 & 2.5 & 30 & 3.37 & 20.84 \\
Rating Scale & 64 & 1.33 & 1 & 1.56 & 0 & 7 & 2.45 & 8.43 \\
Volume USD & 21 & 464 & 400 & 381 & 5 & 1500 & 1.1 & 3.81 \\
Volume SEK & 22 & 1222 & 1000 & 930 & 230 & 3750 & 1.5 & 4.83 \\
Volume EUR & 21 & 710 & 500 & 549 & 30 & 1900 & 0.9 & 2.78 \\
\hline
\end{tabular}

Note: All volume variables (Volume USD, Volume SEK, Volume EUR, and Volume) are reported in millions. The volume variable of conventional bonds is denoted in EUR.

\subsection{The bid-ask spread regression}

We perform a correlation analysis between the bid-ask spread and the LOT liquidity measure. We find $62 \%$ correlation between the two measures that signifies a relatively strong dependency between the two measures. In order to check the consistency of our two estimates, we perform a within effects panel regression and we regress the bid-ask spread on the LOT liquidity measure. Table 4 shows the results for this regression. 
Table 4: The bid-ask spread regression

\begin{tabular}{lc}
\hline & $(1)$ \\
VARIABLES & BidAsk \\
\hline \multirow{2}{*}{ LOT } & $0.645^{* *}$ \\
& $(0.285)$ \\
Constant & $30.11^{* * *}$ \\
& $(6.576)$ \\
& \\
& \\
Observations & 236 \\
Number of idgroup & 120 \\
R-squared & 0.099 \\
\hline Robust standard errors in parentheses \\
${ }^{* * *} \mathrm{p}<0.01,{ }^{* *} \mathrm{p}<0.05,{ }^{*} \mathrm{p}<0.1$
\end{tabular}

\subsection{Determinants of the yield spread}

The results for the pooled OLS and the fixed-effects models are reported in Table 5. Based on the overall regression results, the LOT liquidity and the bid-ask spreads are significant and positively related to yield spread. In Model 1, where we only include conventional bonds, the bid-ask spread is significant and positive at the $1 \%$ level, while the LOT liquidity is insignificant. In Model 2, where we include only green bonds, both the LOT liquidity and the bid-ask spread are positive and significant at the $1 \%$ and $5 \%$ level, respectively. Both maturity variables in Model 1 and 2 are significant. However, the Maturity coefficient is negative for green bonds and the coefficient is positive for conventional bonds. A positive relationship between maturity and yield spreads is usually expected for investment grade bonds (Campbell \& Taksler 2003). Although our sample of green bonds belong to investment grade bonds, the Maturity variable of green bonds is negatively associated with yield spreads. The negative relationship between maturity and yield spreads is more expected for speculative grade bonds (Helwege \& Turner 1999).

In Model 3, which combines the subsamples of green and conventional bonds, the interaction term $L O T \times$ Green is positive and significant at the $5 \%$ level. This means when the LOT measure increases by $1 \mathrm{bp}$, the yield spread goes up by $0.72 \mathrm{bp}$. BidAsk $\times$ 
Green is insignificant, however, implying that the bid-ask spread does not influence yield spreads for green bonds. The opposite applies for conventional bonds where the interaction term LOT $\times$ Conventional is insignificant, which suggests the LOT measure does not explain the yield spread of conventional bonds. The coefficient of BidAsk $\times$ Conventional is positive and significant at the $5 \%$ level implying that the yield spread increases by $0.7 \mathrm{bp}$ when the bid-ask spread goes up by $1 \mathrm{bp}$. The size of our LOT liquidity premium on yield spreads for green bonds is about two times stronger than LOT liquidity measure for US investment grade corporate bonds studied by (Chen et al. 2007). Furthermore, the coefficient of Debt/Capital is positive and significant at the $10 \%$ level. This result is expected since the higher leverage ratio is associated with an increase in yield spreads.

In Model 4, only green bonds are included in the fixed-effects panel regression, the interaction variables $L O T \times y r 2013, L O T \times y r 2014$, and $L O T \times y r 2015$ are positive and significant at the $1 \%, 1 \%$ and $10 \%$ level, respectively. The coefficient of $L O T \times y r 2013$ is particularly high, indicating the liquidity risk was the highest in 2013 for green bonds. In 2013, a 1 bp increase in LOT measure lead to 12.40 bp increase in yield spread. Over the sample period, however, the effect of liquidity risk on green bonds' yield spread decreases. Furthermore, in 2016 the effect of liquidity risk on yield spread becomes insignificant. The LOT liquidity's explanatory power in combination with control variables is $37 \%$ (within $R^{2}$ ).

Table 5: The determinants of bonds' yield spread

\begin{tabular}{lllll}
\hline Variables & Model 1 & Model 2 & Model 3 & Model 4 \\
\hline$y r=2014$ & -27.22 & -21.85 & -13.79 & $208.2^{* * *}$ \\
& $(38.20)$ & $(31.39)$ & $(27.32)$ & $(45.43)$ \\
$y r=2015$ & -12.64 & -7.412 & 83.32 & $239.8^{* * *}$ \\
& $(50.23)$ & $(30.86)$ & $(68.54)$ & $(58.79)$ \\
$y r=2016$ & 24.09 & -0.0883 & 111.9 & $252.6^{* * *}$ \\
& $(40.08)$ & $(29.93)$ & $(76.91)$ & $(62.94)$ \\
LOT & -3.051 & $1.613^{* * *}$ & - & - \\
\multirow{2}{*}{ BidAsk } & $(2.227)$ & $(0.472)$ & & -
\end{tabular}




\begin{tabular}{|c|c|c|c|c|}
\hline & $(0.906)$ & $(0.210)$ & & \\
\hline LOT $\times$ Conventional & - & - & $\begin{array}{l}-1.182 \\
(1.736)\end{array}$ & 一 \\
\hline LOT $\times$ Green bond & - & - & $\begin{array}{l}0.720^{* *} \\
(0.336)\end{array}$ & - \\
\hline BidAsk $\times$ Conventional & - & - & $\begin{array}{l}0.702^{* *} \\
(0.304)\end{array}$ & - \\
\hline BidAsk $\times$ Green bond & - & - & $\begin{array}{l}-0.206 \\
(0.264)\end{array}$ & - \\
\hline LOT×yr2013 & - & - & - & $\begin{array}{l}12.40^{* * *} \\
(2.446)\end{array}$ \\
\hline LOT $\times y r 2014$ & - & - & - & $\begin{array}{l}0.849^{* * *} \\
(0.270)\end{array}$ \\
\hline LOT $\times y r 2015$ & - & - & - & $\begin{array}{l}0.369 * \\
(0.205)\end{array}$ \\
\hline LOT× yr2016 & - & - & - & $\begin{array}{l}0.252 \\
(0.231)\end{array}$ \\
\hline Income/Sales & $\begin{array}{l}-1.474 \\
(1.316)\end{array}$ & $\begin{array}{l}-8.534 \\
(6.922)\end{array}$ & $\begin{array}{l}-2.122 \\
(1.436)\end{array}$ & $\begin{array}{l}11.50 \\
(9.903)\end{array}$ \\
\hline Debt/Assets & $\begin{array}{l}-8.088 \\
(143.6)\end{array}$ & $\begin{array}{l}-28.41 \\
(21.61)\end{array}$ & $\begin{array}{l}-110.9 \\
(86.10)\end{array}$ & $\begin{array}{l}-71.95 \\
(56.45)\end{array}$ \\
\hline Debt/Capital & $\begin{array}{l}-56.56 \\
(83.33)\end{array}$ & $\begin{array}{l}-5.963^{* *} \\
(2.953)\end{array}$ & $\begin{array}{l}67.16^{*} \\
(37.15)\end{array}$ & $\begin{array}{l}5.769 \\
(8.357)\end{array}$ \\
\hline Interest Coverage & $\begin{array}{l}0.0141 \\
(0.183)\end{array}$ & $\begin{array}{l}1.449^{* *} \\
(0.574)\end{array}$ & $\begin{array}{l}0.633 \\
(0.508)\end{array}$ & $\begin{array}{l}-0.128 \\
(0.405)\end{array}$ \\
\hline Maturity & $\begin{array}{l}11.00^{*} \\
(6.258)\end{array}$ & $\begin{array}{l}-4.764^{* * *} \\
(1.296)\end{array}$ & - & - \\
\hline Government Bond & - & $\begin{array}{l}0.536 \\
(6.108)\end{array}$ & $\begin{array}{l}78.43^{*} \\
(44.35)\end{array}$ & $\begin{array}{l}20.84 \\
(18.37)\end{array}$ \\
\hline Term Slope & - & $\begin{array}{l}6.191 \\
(14.50)\end{array}$ & $\begin{array}{l}149.4^{* *} \\
(65.61)\end{array}$ & $\begin{array}{l}39.25 \\
(30.16)\end{array}$ \\
\hline Rating Scale $=1$ & - & $\begin{array}{l}-54.05^{* * *} \\
(11.97)\end{array}$ & - & - \\
\hline Rating Scale $=2$ & $\begin{array}{l}-19.58 \\
(42.83)\end{array}$ & $\begin{array}{l}-15.13 \\
(15.50)\end{array}$ & - & - \\
\hline Rating Scale $=3$ & $\begin{array}{l}-78.41 \\
(57.80)\end{array}$ & - & - & - \\
\hline Rating Scale $=4$ & $\begin{array}{l}-509.8^{* * *} \\
(128.1)\end{array}$ & - & - & - \\
\hline Rating Scale $=5$ & $\begin{array}{l}-47.33 \\
(43.27)\end{array}$ & $\begin{array}{l}-16.87 \\
(21.16)\end{array}$ & - & - \\
\hline Rating Scale $=6$ & $\begin{array}{l}24.79 \\
(41.77)\end{array}$ & $\begin{array}{l}-20.16 \\
(25.72)\end{array}$ & - & - \\
\hline Rating Scale $=7$ & $\begin{array}{l}15.50 \\
(52.33)\end{array}$ & $\begin{array}{l}199.2^{* * *} \\
(24.91)\end{array}$ & - & - \\
\hline Constant & 68.06 & $103.7^{* * *}$ & -125.6 & $-194.4^{* * *}$ \\
\hline
\end{tabular}




\begin{tabular}{lllll} 
& $(72.27)$ & $(39.11)$ & $(136.7)$ & $(71.56)$ \\
\hline Observations & 116 & 120 & 236 & 120 \\
R-squared & 0.511 & 0.763 & 0.282 & 0.371 \\
\hline
\end{tabular}

Note: Robust standard errors in parentheses. ${ }^{*},{ }^{* *},{ }^{* * *}$ denotes significance at 10,5 , and 1 percent respectively. Model 1 represents a pooled OLS regression for the subsample of conventional bonds. Model 2 represents a pooled OLS regression for the subsample green bonds. Model 3 represents a fixed effects regression with robust clustered standard errors at bond level for both bonds. Model 4 represents a fixed effects regression for the subsample of green bonds.

\section{Conclusions}

The green bond market has been growing in recent years. This paper investigates the relationship between liquidity risk and yield spread for both green and conventional bonds. We employ two measures of liquidity: the LOT measure and the bid-ask spread. Contrary to the initial expectation, the descriptive evidence indicates that green bonds are, on average, more liquid when compared to conventional bonds, over the years 2014-2016. The regression results reveal that both the LOT liquidity and the bid-ask measure are positively related to the yield spread. However, for the fixed-effects model, only the LOT measure turns out to be relevant for green bonds. We also find that the effect of LOT vanishes over time, pointing out that, for green bonds, the impact of liquidity risk on yield spread has become negligible in most recent years. This latter observation may hint at a growing maturity of green bonds markets.

\section{References}

Amihud, Y. (2002), 'Illiquidity and stock returns: cross-section and time-series effects', Journal of financial markets 5(1), 31-56.

Amihud, Y. \& Mendelson, H. (1980), 'Dealership market: Market-making with inventory', Journal of Financial Economics 8(1), 31-53.

Amihud, Y. \& Mendelson, H. (1986), 'Asset pricing and the bid-ask spread', Journal of Financial Economics 17(2), 223-249.

Amihud, Y., Mendelson, H., Pedersen, L. H. et al. (2006), 'Liquidity and asset prices', Foundations and Trends ${ }^{\circledR}$ in Finance 1(4), 269-364. 
Bagehot, W. (1971), 'The only game in town', Financial Analysts Journal 27(2), 12-14.

Bloomberg (2017), Investors are willing to pay a "green" premium, Bloomberg new energy finance report.

Brandt, M. W. \& Kavajecz, K. A. (2004), 'Price discovery in the us treasury market: The impact of orderflow and liquidity on the yield curve', The Journal of Finance 59(6), 2623-2654.

Buchanan, J. M. \& Tullock, G. (1975), 'Polluters' profits and political response: Direct controls versus taxes', The American Economic Review 65(1), 139-147.

Campbell, J. Y. \& Taksler, G. B. (2003), 'Equity volatility and corporate bond yields', The Journal of Finance 58(6), 2321-2350.

CBI (2015), Scaling up green bond markets for sustainable development, Consultation paper, Climate Bonds Initiative.

Chen, L., Lesmond, D. A. \& Wei, J. (2007), 'Corporate yield spreads and bond liquidity', The Journal of Finance 62(1), 119-149.

Clapp, C. (2014), 'Climate finance: capitalising on green investment trends', The Way Forward in International Climate Policy p. 44.

Cochu, A., Glenting, C., Hogg, D., Georgiev, I., Skolina, J., Elsinger, F., Jespersen, M., Agster, R., Fawkes, S. \& Chowdury, T. (2016), Study on the potential of green bond finance for resource-efficient investments, Report, European Commission.

Collin-Dufresn, P., Goldstein, R. S. \& Martin, J. S. (2001), 'The determinants of credit spread changes', The Journal of Finance 56(6), 2177-2207.

Dick-Nielsen, J., Feldhütter, P. \& Lando, D. (2012), 'Corporate bond liquidity before and after the onset of the subprime crisis', Journal of Financial Economics 103(3), 471492.

EUROPA (2017), 'Commission takes further steps to enhance business transparency on social and environmental matters', European Commission-Press Release Database .

Flaherty, M., Gevorkyan, A., Radpour, S. \& Semmler, W. (2017), 'Financing climate policies through climate bonds-a three stage model and empirics', Research in International Business and Finance 42, 468-479.

Han, S. \& Zhou, H. (2008), 'Effects of liquidity on the nondefault component of corporate yield spreads: evidence from intraday transactions data'.

Helwege, J. \& Turner, C. M. (1999), 'The slope of the credit yield curve for speculativegrade issuers', The Journal of Finance 54(5), 1869-1884.

Inderst, G., Kaminker, C. \& Stewart, F. (2012), 'Defining and measuring green investments', OECD Working Papers on Finance, Insurance and Private Pensions (24). 
IPCC (2013), Climate change 2013: The physical science basis, Contribution of working group contribution of working group i to the fifth assessment report of the intergovernmental panel on climate change [stocker, t.f., d. qin, g.-k. plattner, m. tignor, s.k. allen, j. boschung, a. nauels, y. xia, v. bex and p.m. midgley (eds.)], IPCC.

Jarrow, R. A. (1978), 'The relationship between yield, risk, and return of corporate bonds', The Journal of Finance 33(4), 1235-1240.

Kane, S. \& Shogren, J. F. (2000), 'Linking adaptation and mitigation in climate change policy', Climatic Change 45(1), 75-102.

Karpf, A. \& Mandel, A. (2017), Does it pay to be green? Available at https://ssrn.com/abstract=2923484.

Lesmond, D. A., Ogden, J. P. \& Trzcinka, C. A. (1999), 'A new estimate of transaction costs', The Review of Financial Studies 12(5), 1113-1141.

Lin, Y.-M., You, S.-J. \& Huang, M.-S. (2012), 'Information asymmetry and liquidity risk', International Review of Business Research Papers 8(1), 112-131.

Longstaff, F. A., Mithal, S. \& Neis, E. (2005), 'Corporate yield spreads: Default risk or liquidity? New evidence from the credit default swap market', The Journal of Finance 60(5), 2213-2253.

Mackenzie, C. \& Ascui, F. (2009), 'Investor leadership on climate change: an analysis of the investment community's role on climate change, and snapshot of recent investor activity', UN Global Compact, New York, NY.

OECD (2017), 'Mobilising bond markets for a low-carbon transition'.

URL: /content/book/9789264272323-en

Preclaw, R. \& Bakshi, A. (2015a), The cost of being green., Report, Barclays Credit Research.

Preclaw, R. \& Bakshi, A. (2015b), The cost of being green, Barclays credit research.

the High-Level Expert Group (2017), Financing a sustainable european economy, Interim report, july 2017, European Commission.

the World Bank (2015), Green bonds attract private sector climate finance, World bank brief.

Utz, S., Weber, M. \& Wimmer, M. (2016), 'German Mittelstand bonds: yield spreads and liquidity', Journal of Business Economics 86(1-2), 103-129.

Zerbib, O. D. (2017), The green bond premium. Available at SSRN: https://ssrn.com/abstract=2889690.

\section{Appendix}

\section{Tables}


Table 6: Conventional bonds' average cost of sell trades $\left(\alpha_{1, \mathrm{j}}\right)$, buy trades $\left(\alpha_{2, \mathrm{j}}\right)$, and LOT liquidity estimate $\left(\alpha_{2, \mathrm{j}^{-}} \alpha_{1, \mathrm{j}}\right)$ in \%

\begin{tabular}{ccccc}
\hline Year & No.Bonds & $\alpha_{1}$ & $\alpha_{2}$ & LOT \\
\hline 2013 & 18 & -0.1249 & 0.1269 & 0.2517 \\
2014 & 25 & -0.1167 & 0.1028 & 0.2195 \\
2015 & 31 & -0.1320 & 0.1316 & 0.2635 \\
2016 & 42 & -0.1693 & -0.1659 & 0.3352 \\
\hline
\end{tabular}

Table 7: Green bonds' average cost of sell trades $\left(\alpha_{1, \mathrm{j}}\right)$, buy trades $\left(\alpha_{2, \mathrm{j}}\right)$, and LOT liquidity estimate $\left(\alpha_{2, \mathrm{j}}-\alpha_{1, \mathrm{j}}\right)$ in \%

\begin{tabular}{ccccc}
\hline Year & No.Bonds & $\alpha_{1}$ & $\alpha_{2}$ & LOT \\
\hline 2013 & 3 & -0.0970 & 0.0836 & 0.1810 \\
2014 & 15 & -0.0985 & 0.0488 & 0.1509 \\
2015 & 38 & -0.1121 & 0.0679 & 0.1800 \\
2016 & 64 & -0.1339 & 0.0609 & 0.1947 \\
\hline
\end{tabular}

Table 8: Descriptive statistics of green and conventional bonds and firm-level data over all years

\begin{tabular}{lcrrrrrrr}
\hline Variables & Obs & Mean & Median & SD & Min & Max & Skewness & Kurtosis \\
\hline Conventional & & & & & & & & \\
Income/Sales & 116 & 16.82 & 6.74 & 22.61 & -46.95 & 89.38 & 0.96 & 3.88 \\
Debt/Assets & 116 & 0.39 & 0.37 & 0.29 & 0 & 2.11 & 1.88 & 12.57 \\
Debt/Capital & 116 & 0.71 & 0.74 & 0.28 & 0 & 1.4 & -0.4 & 3.53 \\
Interest Coverage & 116 & 9.97 & 2.8 & 38.12 & -15.75 & 395.9 & 9.11 & 92.23 \\
& & & & & & & & \\
Green & & & & & & & & \\
Income/Sales & 120 & 0.23 & 0.48 & 1.27 & -3.19 & 2.01 & -1.75 & 5.41 \\
Debt/Assets & 120 & 0.56 & 0.49 & 0.23 & 0.01 & 0.93 & -0.27 & 2.64 \\
Debt/Capital & 120 & 0.87 & 0.88 & 0.73 & 0.09 & 7.76 & 7.52 & 69.71 \\
Interest Coverage & 120 & -3 & 1.09 & 18.73 & -82.68 & 59.92 & -2.17 & 11.42 \\
\hline
\end{tabular}

